\title{
ANALYSIS OF THE TEMPORAL AND SPATIAL CONTROLLING FACTORS IN AFFECTING THE ACCURACY OF LANDSLIDE PREDICTING MODEL AT TAIWAN
}

\author{
Teng-To Yu${ }^{1, *}$, Youg-Sin Cheng ${ }^{1}$, Wen-Fei Peng ${ }^{2}$, Pei-Lin Lee \\ ${ }^{1}$ Deptarment of Resources Engineering, National Cheng Kung University, Tainan, Taiwan- yutt@ mail.ncku.edu.tw \\ ${ }^{2}$ Geoinformatics Research Center, National Cheng Kung University, Tainan, Taiwan
}

KEYWORDS: controlling factor, LSM, AUC, model

\begin{abstract}
:
Most of the landslides are triggered by rainfall, earthquake or the joint effect from both. Landslide inventory map by GIS via remote sensing offer the spatial distribution of it across certain external event. The landslide model thus been trained to link the occurrence and non-occurrence of individual mass wasting on top of proposing factors/layers. Chosen factors with various calculated weighting values becomes as the base of predicting the region and condition for future landslide called as Landslide Susceptibility Mapping (LSM). It is found that the temporal factor has less AUC values than spatial factors at Taiwan, after examining the 20 years catalog and thousand cases of landslide island wide. Different resolution of DEM and NDVI from satellite image, hyper spectrum and LiDAR are utilized to resolve the degree of impact of it. The require accuracy and resolution of base map is directly link to the accuracy and also minimum mapping size of catalog, and the non-linear relationship of external factors still cannot be well predicted by the training model. To achieve better accuracy of LSM the temporal and non-linearity properties should be addressed, especially under the influence of global warming.
\end{abstract}

\section{INTRODUCTION:}

Accuracy of landslide predicting model is generally around $80 \%$, it is depending on the difference of time and location between the training and testing model. Due to the complexity of nature environment and triggering factors. Such work could be group into two sub-domains, one is to predict the upcoming landslides at the same study region; or to calculate the possibility of landslide occurrence at other region. Either one of these cases that require to build a training model with known parameters, such as terrain, geological structure, rainfall etc. There are more than 64 parameters could affect the occurrence of landslide, and some of it cannot be quantified (Koukis \& Zioukas, 1991). Not all the factors shall affect the occurrence of a landslide, for example that rain infiltration to trigger the landslide is only by considering the soil, slop and rainfall properties (Iverson, 2000). Earthquake induced landslide is correlates with distance from the earthquake source, slope steepness, and rock type (Keefer, 2000). The prediction of landslides, caused by interaction of factors vary over areas and time, pose limitations to the tasks of mapping and analyzing the spatiotemporal patterns of relationships between landslide occurrence and causative factors (Metternicht et al., 2005). The occurrence of landslides in general is a function of the interaction of natural phenomena such as unfavorable lithology, stratigraphic sequence, structural makeup, geomorphological setting, earthquake, rainfall, etc. (Ayalew et al., 2004). For layers super impost-based analyses, factors are directly or indirectly related to the formation of landslides are named as event-controlling parameters. It is believed that the accuracy of predicting model increases when all event controlling parameters are considered within the process, but it is difficult to get all the required data in time and also with required resolution. Razak (2011) indicates that to analysis the topographic feature link to the landslide vis LiDAR data, require 1.69 points $/ \mathrm{m}^{2}$. However, it takes at least 5.69 points $/ \mathrm{m}^{2}$ to perform evaluation with much detail aspect. The various spatial resolution of LiDAR data taken at the same location in Southern Taiwan is shown in Figure 1, the detail structures and minor golly could be found on right panel (Yen, 2005). For this reason, some of the analyses depend only on lithology and the topographic attributes of the region such as elevation, slope gradient, aspect and curvature. Therefore, the predicting accuracy is not satisfied and to tune the model of better accuracy by considering in depth parameter is the aim of this work.
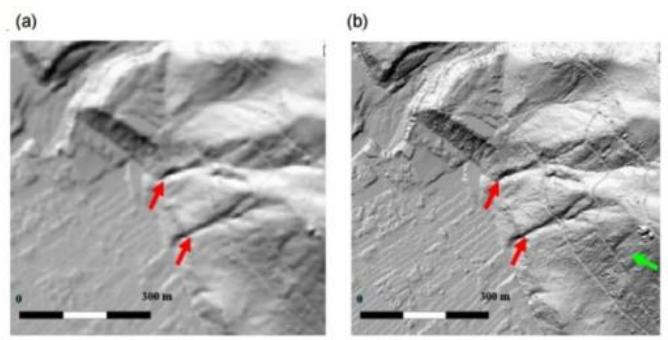

Figure 1: Comparison of two grey shadow charts with various $\mathrm{LiDAR}$ resolution data

(a) $5 \mathrm{~m}$; (b) $1 \mathrm{~m}$ interval (Yen, 2005). 


\section{DATA AND ANALYSIS METHOD:}

Aerial LiDAR with 1-meter ground resolution gathered at 2014 is utilized as base data set, meanwhile remote sensing imagery of 2-meter resolution acquired at 2015 to detect the change of land surface thus to build up the landslide catalog for model accuracy checking. The distribution of slope in the study area is shown at Figure 2 . The high rugged testing region is located at Southern Taiwan, more than $30 \%$ slope count for $2 / 3$ of the region. Two more aerial LiDAR acquired at early and late 2015 is exploited to act as information source of detecting temporal discrepancy of DTM and also parameters that derived from DTM such as slope, aspect etc.

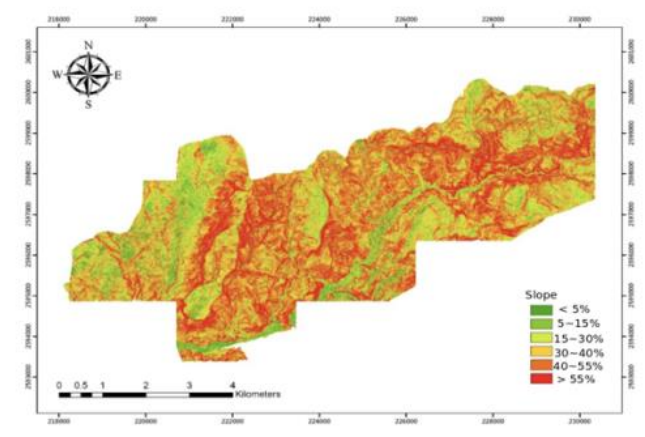

Figure 2: The slope distribution layer of the study area located at Southern Taiwan.

Study flow chart of this work is illustrated at Figure 3, the operation of converting DTM into hydraulic parameters is carried out by Hydrology tools of ArcGIS. The handling parameters of this task have set the same for all the data set to eliminate the possible human caused bias.

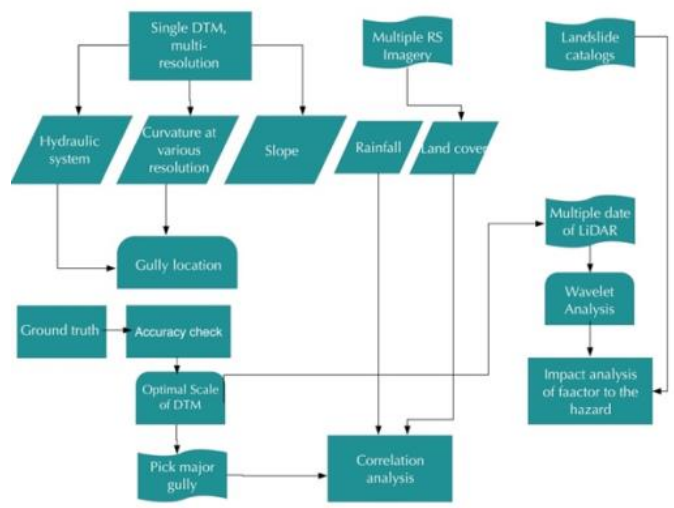

Figure 3: The working flow chart and relationship to the imported data.

Imported DTM data is automatically processed by Wavelet to detect the location and size of gully. Result of this GIS output reveal the correlating relationship between extracted hydraulic system via various DTM resolution listed at figure 4 . It is found that the detected noise is higher at coarse resolution data. This outcome requires advance processing to match the ground truth condition.
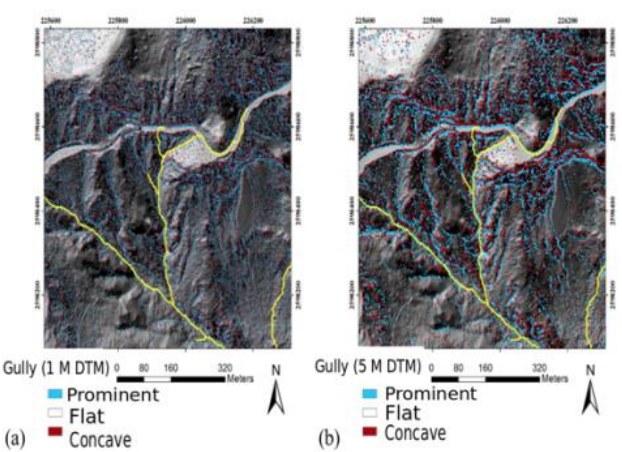

Figure 4: Automatic extract hydraulic gully from (a) 1 $\mathrm{m}$ resolution DTM, (b) $5 \mathrm{~m}$ resolution DTM gathered at the same place and time.

Another important information of land cover is derived from NDVI (Normalized Difference Vegetation Index) via multispectral remote sensing images. Quad treeBased segmentation to perform the multiresolution segmentation with eCognition software, the result shown at Figure 5. Tree type and CHM (Crown Height Model) is also considered.

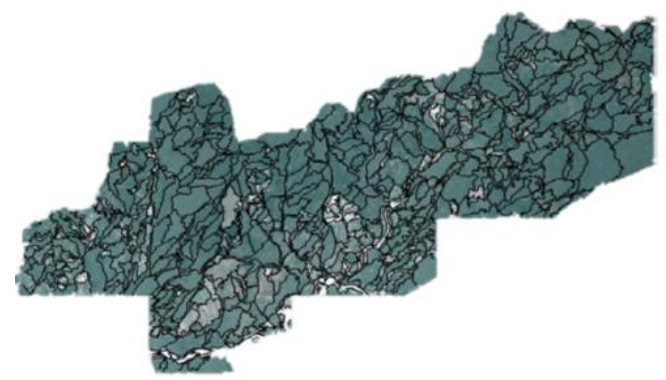

Figure 5: The layer of NDVI segmentation to present the status of land cover.

Layer of rainfall is interpolated from official rain gauge records of the time. A strong rainfall event that is defined as more than $200 \mathrm{~mm} /$ day, an example of rainfall layer at the study area is shown at Figure 6.

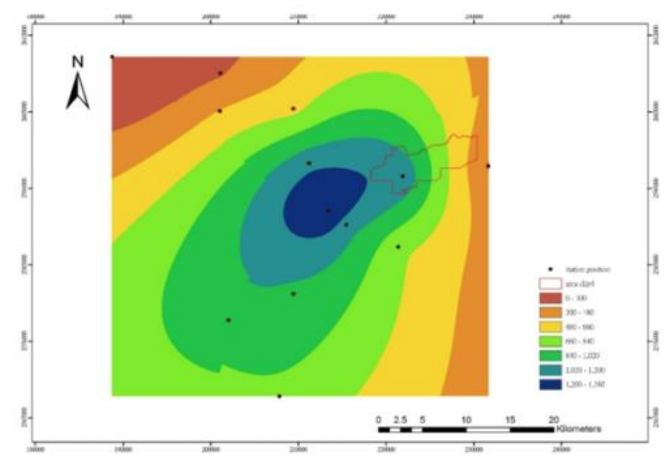

Figure 6: The interpolated rainfall layer for an example strong rainfall event at study area.

The yearly landslide catalog of the study area is listed at Figure 7, this area is stroke by heavy rainfall caused by typhoon at the year of 2009 and 2010 , this is the most important causative factor of frequent landslide at the study region. 


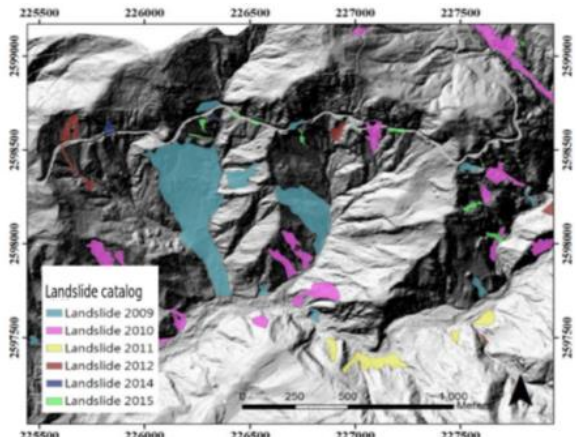

Figure 7: The yearly landslide catalog at study area.

The gully is extracted from three stages of aerial LiDAR data first, after the redeem handling with established rules from ground truth the gully density map of three different time is deploy at Figure 8 to 10, respectively. Density of gully superimposed on top of layers of all kind to establish a training model of the same year of data gathering and also included the data at matching time of trigger factor. Therefore, three models with various factor ranking and also the weighting coefficient is assembled.

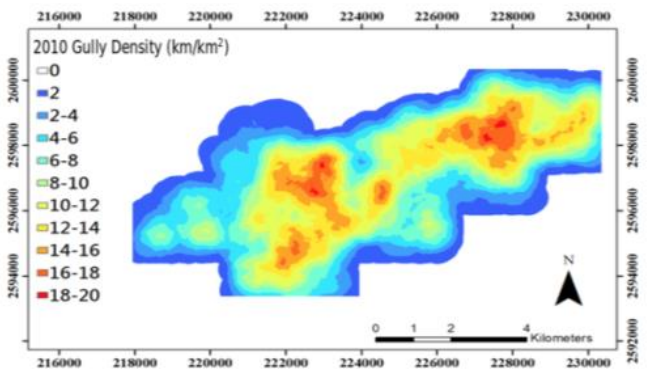

Figure 8: The gully density calculated from LiDAR data of year 2010.

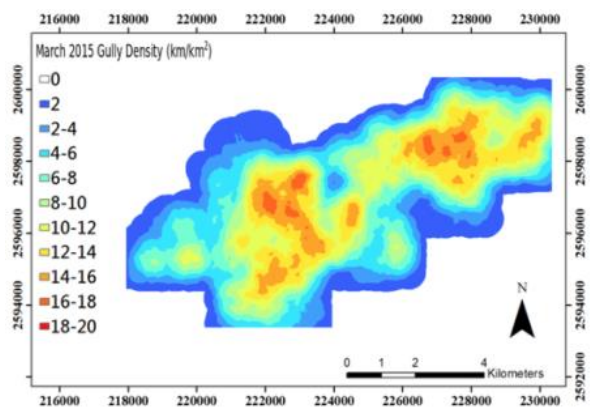

Figure 9: The gully density calculated from LiDAR data of March 2015.

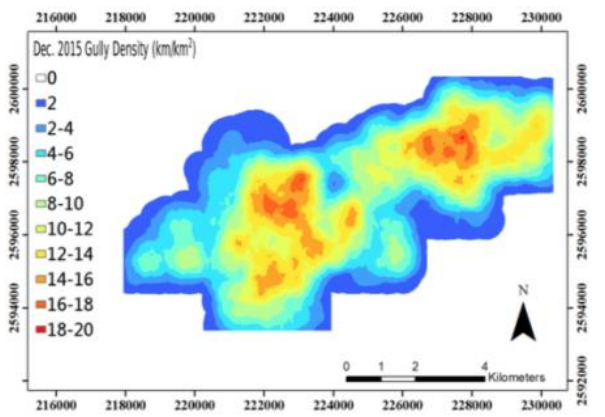

Figure 10: The gully density calculated from LiDAR data of Dec. 2015.

\begin{tabular}{|c|c|c|c|c|c|c|}
\hline \multicolumn{7}{|c|}{ Slope } \\
\hline class & $\begin{array}{l}\text { Erosion } \\
\text { area }\end{array}$ & \begin{tabular}{|l} 
Erosional \\
area ratio
\end{tabular} & \begin{tabular}{|l|} 
The \\
coefficient of \\
variation
\end{tabular} & $\begin{array}{l}\text { Accumulation } \\
\text { area }\end{array}$ & \begin{tabular}{|l|} 
Accumulation \\
area ratio
\end{tabular} & \begin{tabular}{|l|l|}
$\begin{array}{l}\text { The } \\
\text { coefficient of } \\
\text { variation }\end{array}$ \\
\end{tabular} \\
\hline$<5 \%$ & 17 & 0.006719 & \multirow{6}{*}{0.83415} & 54 & 0.028739 & \multirow{6}{*}{0.52469} \\
\hline $5 \sim 15 \%$ & 144 & 0.056917 & & 191 & 0.10165 & \\
\hline $15 \sim 30 \%$ & 928 & 0.366798 & & 491 & 0.261309 & \\
\hline $30 \sim 40 \%$ & 806 & 0.318577 & & 498 & 0.265035 & \\
\hline $40 \sim 55 \%$ & 512 & 0.202372 & & 406 & 0.216072 & \\
\hline$>55 \%$ & 123 & 0.048617 & & 239 & 0.127195 & \\
\hline \multicolumn{7}{|c|}{ Rainfall } \\
\hline $480 \sim 540$ & 893 & 0.458419 & \multirow{4}{*}{0.6148} & 463 & 0.380131 & \multirow{4}{*}{0.46214} \\
\hline $540 \sim 600$ & 551 & 0.282854 & & 243 & 0.199507 & \\
\hline $600 \sim 660$ & 451 & 0.231520 & & 105 & 0.086207 & \\
\hline $780 \sim 840$ & 53 & 0.027207 & & 407 & 0.334154 & \\
\hline \multicolumn{7}{|c|}{ Plantation } \\
\hline Coniferous & 595 & 0.330923 & \multirow{4}{*}{0.30851} & 641 & 0.526273 & \multirow{4}{*}{0.65079} \\
\hline Mixed Forest & 221 & 0.122914 & & 182 & 0.149425 & \\
\hline Bamboo & 484 & 0.269188 & & 252 & 0.206897 & \\
\hline Shrubbery & 498 & 0.276974 & & 143 & 0.117406 & \\
\hline
\end{tabular}

Table 1: Evaluating table of all kinds impact factors to landslides

When individual factor be examined with the ratio of landslide occurrence, the 15 40\% slope dominated. The rainfall 480 540 account for almost $46 \%$ of newly landslide and the mixed forest contribute the least area of collapsing as shown at Table 1. This statistic outcomes demonstrate the disadvantages of single factor analysis. While classify the degree of gully erosion by $0 \sim 0.5,0.5 \sim 1,1 \sim 1.5,1.5 \sim 2$ and above 2 meters into five groups and defined as slight, mild, moderate, seriously and serious. Land cover with shrubbery have weaker resistance to erosion. Slope from $15 \sim 55 \%$ have most of landslide occurred but slope above $55 \%$ have very little landslide as Table 2 shown.

By compare the gully density of these three stages, it is found that most of the newly landslide is occurred within gully density of $\left(12 \sim 16 \mathrm{~km} / \mathrm{km}^{2}\right)$ and it is concentrated at the region of upstream which are dominated by head ward erosion from March to December 2015. But $20.58 \%$ collapsed ratio located within gully density of $6 \sim 8\left(\mathrm{~km} / \mathrm{km}^{2}\right)$, it also adjacent to the main river that indicate the landslides are caused by slope foot erosion instead of head ward erosion from 2010 to 2014 shown at Table 3 .

The density of gully gradually decreased with time, the mass area of newly landslide at 2010 is the consequences of typhoon Morakot at 2009 that brought record breaking precipitation at the region, $3060 \mathrm{~mm}$, this is also why the identified gully density is higher at this stage of time.

\begin{tabular}{|l|l|l|l|l|l|l|}
\hline & lass & Slight \% & Mild \% & Moderate\% & Seriously\% & Serious\% \\
\hline \multirow{4}{*}{ plantation } & Mixed Forest & 64.569 & 30.303 & 4.662 & 0.466 & 0 \\
\cline { 2 - 7 } & Bamboo & 94.717 & 5.283 & 0 & 0 & 0 \\
\cline { 2 - 7 } & Coniferous & 56.275 & 35.931 & 6.209 & 1.189 & 0.793 \\
\cline { 2 - 7 } & Shrubbery & 31.099 & 42.627 & 23.324 & 2.681 & 0.268 \\
\hline \multirow{5}{*}{ slope } & $<5 \%$ & 78.947 & 21.053 & 0 & 0 & 0 \\
\cline { 2 - 7 } & $5 \sim 15 \%$ & 57.868 & 31.472 & 8.122 & 2.538 & 0 \\
\cline { 2 - 7 } & $15 \sim 30 \%$ & 58.774 & 31.264 & 8.966 & 0.766 & 0.230 \\
\cline { 2 - 7 } & $30 \sim 40 \%$ & 50.123 & 36.483 & 11.504 & 1.561 & 0.329 \\
\cline { 2 - 7 } & $40 \sim 55 \%$ & 51.259 & 31.990 & 13.728 & 2.645 & 0.378 \\
\hline & $>55 \%$ & 65.882 & 18.235 & 11.765 & 2.353 & 1.765 \\
\hline \multirow{5}{*}{ rainfall } & $480 \sim 540$ & 78.739 & 18.018 & 2.342 & 0.901 & 0 \\
\cline { 2 - 7 } & $540 \sim 600$ & 53.680 & 28.725 & 15.978 & 1.616 & 0 \\
\cline { 2 - 7 } & $600 \sim 660$ & 54.362 & 38.479 & 6.711 & 0.447 & 0 \\
\cline { 2 - 7 } & $780 \sim 840$ & 90.000 & 6.000 & 0 & 2.000 & 2.000 \\
\cline { 2 - 7 } & $1020 \sim 1200$ & 31.454 & 54.006 & 11.573 & 1.187 & 1.780 \\
\hline
\end{tabular}

Table 2: Degree of gully erosion to the class of all kind factors 


\begin{tabular}{|c|c|c|c|c|}
\hline $\begin{array}{l}\text { Gully Density } \\
\left(\mathrm{km} / \mathrm{km}^{2}\right)\end{array}$ & $\begin{array}{l}2010 \sim 2014 \\
\text { landslide area }\left(\mathrm{m}^{2}\right)\end{array}$ & $\%$ & $\begin{array}{l}2015 \\
\text { landslide area }\left(\mathrm{m}^{3}\right)\end{array}$ & $\%$ \\
\hline $2 \sim 4$ & 15424 & 1.10 & -- & $\cdots$ \\
\hline $4 \sim 6$ & 183184 & 13.11 & 3504 & 1.70 \\
\hline $6 \sim 8$ & 287808 & 20.59 & 9232 & 4.48 \\
\hline $8 \sim 10$ & 144640 & 10.35 & 1808 & 0.88 \\
\hline $10 \sim 12$ & 200368 & 14.34 & 27728 & 13.46 \\
\hline $12 \sim 14$ & 217760 & 15.58 & 67280 & 32.67 \\
\hline $14 \sim 16$ & 210640 & 15.07 & 93568 & 45.43 \\
\hline $16 \sim 18$ & 123936 & 8.87 & 2832 & 1.38 \\
\hline $18 \sim 20$ & 13760 & 0.98 & -- & - \\
\hline
\end{tabular}

Table 3: Newly landslide area to the gully density

\section{CONCLUSION AND DISCUSSION:}

The accuracy of the landslide prediction model is mostly done by ROC method (Corsini \& Mulas, 2017). By calculating the area under the ROC curve (AUC), higher the area the better predicting result. When a landslide catalog caused by single trigger event (earthquake or rainfall) been separated into two parts to serve as training and testing set. Then calculate the contribution of landslide influence factors and ranking by the degree of its importance. Once the model been constructed then alter the layer of triggering factors to predict the potential of landslide both at location and magnitude. If the prediction is perfectly match to the reality then AUC is $100 \%$, such process has been introduced to form an early warning system for evacuate civilian few hours before the possible nature hazard at Taiwan. While using result of training set to map the future landslide potential for the same place, the AUC is around $80 \%$. If the equation is utilized to forecast the landslide potential at different place, then the AUC might drop to 70 75\% at Taiwan (Lee, 2016). The unstable index method to reveal the weighting of various impact factors shown that both temporal and spatial resolution of base data shall control the degree of LSM accuracy. For the examined case, the rainfall is the most important trigger factor for landslide occurrence at Taiwan. The development of gully that could only be found by high resolution LiDAR also imply that head ward erosion is the key feature of landslide at slope 15 55\%. However, if the precipitation exceeds the threshold then the cut off of slope foot.

Rainfall, earthquake and combination of both trigger vast amount of mass wasting at Taiwan, it is highly dependent with the magnitude and location of the event. The non-linear property is also found, critical phenomena are found at amount of rainfall and slope. Neither the larger the amount of rainfall nor the higher of the slope shall hold more amount of landslide. The Peak Ground Acceleration (PGA) associated with earthquake needed to be considered to evaluate the LSM, but the effect of it decreased with time. The degree of this influence drop back to normal within five years, for the case of magnitude 7.3 Chi-Chi earthquake at 1999 (Lin et al., 2004).

\section{ACKNOWLEDGEMENT:}

This work is fully support by the Ministry of Science and Technology, Taiwan under project no. MOST 1062119-M-006-011. Remote Sensing images of FormoSAT-2 are provided by NSPO, Taiwan. LiDAR data are collected by OPTECH dual laser beam operated by Chung-Sing Survey company, Taiwan.
Handling of point clouds and GIS shapefile are support by Satellite Geo-Informatics Research Center, NCKU.

\section{REFERENCE:}

Ayalew, L., Yamagishi, H. \& Ugawa, N. Landslides (2004) 1: 73. https://doi.org/10.1007/s10346003-0006-9

Corsini, A. \& Mulas, M. (2017) Use of ROC curves for early warning of landslide displacement rates in response to precipitation (Piagneto landslide, Northern Apennines, Italy), Landslides, 14: 1241.

Iverson, Richard M. (2000) Landslide triggering by rain infiltration, WATER RESOURCES RESEARCH, Vol. 36, No. 7, 1897-1910.

Keefer, David K. (2000) Statistical analysis of an earthquake-induced landslide distribution - the 1989 Loma Prieta, California event, Engineering Geology 58, 231-249.

Koukis, G., C. Ziourkas (1991) Slope instability phenomena in Greece: A statistical analysis, Bulletin of Engineering Geology and the Environment, Volume 43, Number 1, pp.47-60.

Lee, P. L. (2016) Restoration Efficiency Evaluating by Automatic Changing Detection with Large-Scale Remote Sensing Images, Dept. Resources Eng., Ph.D. Dissertation, National Cheng Kung University, Taiwan.

Lin, C. W., C. L. Shieh, B. D. Yuan, Y. C. Shieh, S. H. Liu, S. Y. Lee (2004) Impact of Chi-Chi earthquake on the occurrence of landslides and debris flows: example from the Chenyulan River watershed, Nantou, Taiwan, Engineering Geology, 71, 1-2, 49-61.

Metternicht, G., L. Hurni, R. Gogu (2005) Remote sensing of landslides: An analysis of the potential contribution to geo-spatial systems for hazard assessment in mountainous environments, Remote Sensing of Environment 98, $284-303$.

Razak, K.A., Straatsma, M.W., van Westen, C.J., Malet, J.P., de Jong, S.M. (2011), Airborne laser scanning of forested landslides characterization: Terrain model quality and visualization, ELSEVIER Journal of Geomorphology vol.126 p.186- 200

Yen, H. Y. (2005) The Application and Accuracy analysis for digital terrain data with LiDAR, Dept. Earth Sciences, master thesis, National Cheng Kung University, Taiwan. 